\title{
EXPLOTACION DIRECTA O MEDIANERIA EN EL VIN̄EDO CANARIO DURANTE EL SIGLO XVIII: ESTRATEGIAS PARA UNA CRISIS
}

\author{
ANTONIO M. MACIAS HERNANDEZ \\ Universidad de La Laguna
}

De entre las diversas relaciones contractuales establecidas en torno a la posesión y uso de la tierra, la medianería o aparcería es, sin duda, una de las más complejas. Así, desde Adam Smith hasta los neoclásicos, ha sido considerada desde una perspectiva fundamentalmente negativa - tesis compartida por algunos autores para el caso isleño ${ }^{1}$-, en cuanto que reduce la capacidad de capitalización agraria por parte del propietario, al tiempo que el medianero se beneficia de dicha capitalización, pues no dispone de los recursos suficientes para proporcionar su correspondiente contribución al coste marginal de aquélla ${ }^{2}$. Por su parte, el análisis marxista de la aparcería, enriquecido indudablemente desde su primitiva formulación, destaca su relevante significado en la fase de transición del feudalismo al capitalismo ${ }^{3}$. Para I. Wallerstein, Canarias se inscribe en el área definida como semiperiferia, con su producción azucarera y vitícola orientada a los mercados del noroeste europeo, principal mente, y, por consiguiente, con la medianería como relación social de producción dominante ${ }^{4}$. Recientemente, el enfoque neoclásico y marxista han sido revisados. La generalización y persistencia de la aparcería se interpreta como una respuesta a las imperfecciones del mercado de trabajo, al aumento considerable del riesgo y a los elevados costes de transacción presentados por otras

' No consideramos necesario citar aquí todo el material que avala esta afirmación. En nuestra tesis doctoral ha quedado recogido, así como un análisis de la génesis y evolución de esta relación contractual en la agricultura canaria desde el siglo xvi hasta mediados del XIX. Cfr. A. M. Macías Hernóndez, Economía y sociedad en Canarias durante el Antiguo Régimen (tesis doctoral inédita), Universidad Nacional de Educación a Distancia, Madrid, marzo 1985. Con respecto al resto de la tipología de los contratos agrarios, examinados sobre todo desde una perspectiva jurídico-económica, véase J. Peraza de Ayala, 1955.

2 A. F. Robertson, 1980 , pp. $411-412$.

3 C. Marx, 1981, libro tercero, pp. 1021-1034; R. Pearce, 1983.

4. I. Wallerstein, 1979 , p. 150 . No obstante, si la inclusión de Canarias en la semiperiferia de la economía-mundo capitalista queda expresamente indicada por el autor, no alude para nada a la existencia de la medianería en el Archipiélago, entre otras razones por la carencia de trabajos al respecto con anterioridad al que nos ocupa; nosotros hemos supuesto esta alusión, dado que sitúa esta relación contractual en la semiperiferia. 
relaciones contractuales ${ }^{5}$, estudiándose, incluso, su eficiencia a partir de la distinción entre relaciones de producción y de distribución, dando por supuesto la existencia de mercados competitivos ${ }^{6}$.

Nuestra aportación tiene una finalidad bien concreta. Hasta el siglo xvin, y de manera muy esquemática, las relaciones contractuales en el agro isleño presentaban una cierta dualidad: por una parte, en las tierras de pan sembrar predominaba la medianería, seguida del arriendo y del condominio, mientras que los viñedos, cuya producción se destinaba al mercado europeo y, en menor medida, indiano, eran cultivados fundamentalmente mediante mano de obra asalariada. Pero, desde principios de la citada centuria, la medianería se convirtió en el régimen contractual dominante, al sustituir a los otros sistemas de explotación. De esta forma, la clase propietaria logró tres objetivos:

a) Maximizar los beneficios de sus explotaciones en una larga etapa de crisis. A cambio de la mitad de la cosecha, el medianero aportaba casi la totalidad del capital variable y parte del fijo, representado por los aperos de labranza y animales de labor. $Y$ en los casos en que el colono no contaba con los medios precisos para sufragar su correspondiente contribución a los costes de explotación, la clase propietaria se convertía en su intermediario financiero: realizaba los necesarios adelantos a cambio de la participación del aparcero en la cosecha venidera. Además, la propia relación contractual permitía la actuación de determinados mecanismos de carácter extraeconómico que reforzaban la extracción del plustrabajo, tales como el endeudamiento del colonado y la relación de labores sin recibir estipendio alguno ?.

b) Reducir al mínimo el riesgo hasta que mejorase la coyuntura o hubiera otra alternativa de cultivo ${ }^{8}$. En este sentido, la medianería no impidió a la clase propietaria la adopción de otras formas de gestión, por cuanto el medianero carecía de toda protección jurídica para evitar el desahucio?.

3 J. Martínez-Alier, 1983; J. D. Reid, 1976. Sobre el desarrollo de la medianería en economías de plantación bajo las circunstancias económicas citadas, véase a $\mathrm{J}$. R. Mandle, 1983, para el caso del algodón del sur de Estados Unidos, y a V. Stolcke y M. M. Hall, 1983, por lo que respecta a la economía cafetalera brasileña.

- J. M. Caballero, 1983.

7 Cfr. infra.

- M. Bloch, 1978, pp. 374-376; M. Cattini, 1978; G. Biagioli, 1979; G. Cherubini, 1979; P. Malamina, 1979; T. J. Byres, 1983.

- El desarrollo de un nuevo cultivo exportador a mediados del xIx, la cochinilla, desplaź a la medianería por el asalariado, para recurrir nuevamente al mismo en la década de 1880, a raíz de la crisis de este cultivo. Finalmente, la expansión del plátano a principios del xx significó un nuevo retroceso de la medianería: «Hoy la propiedad se encuentra por regla general dividida y repartida y el sistema de aparcería allí establecido de antiguo facilita y asegura la existencia del hombre de campo. Cultivos esmerados, que requieren grandes capitales, han hecho desaparecer de la zona más rica y productiva este sistema patriarcal que aún se conserva en los terrenos restantes y en algunas islas no 
c) Finalmente, haciendo copartícipe al medianero en los beneficios de la explotación, la clase propietaria estimulaba su nivel de productividad y disminuía también la conflictividad social inherente a toda etapa de crisis económica. Todo ello avala la tesis de que las relaciones sociales de producción en la agricultura no evolucionaron de manera lineal e independiente del resto de los procesos económicos y/o extraeconómicos; expresaron en realidad las diversas estrategias de la clase propietaria para maximizar su beneficio, adecuando aquéllas al nivel de desarrollo de las fuerzas productivas ${ }^{10}$.

\section{EXPANSION Y CRISIS DE LA VITICULTURA CANARIA}

A partir de 1525 , es decir, finalizada ya la primera fase del principal proceso colonizador, cuyos inicios dependieron de la divergente cronología de la anexión castellana ", la oferta vitícola de determinadas áreas insulares superó su estrecho marco doméstico, desplazó progresivamente la caña de azúcar desde 1550 y gozó luego de una prolongada etapa de sostenido crecimiento hasta mediados del xvir. La mayor producción y los mejores vinos se obtenían en las terrazas de barlovento de Tenerife, con una cosecha media de 30.00035.000 pipas en su momento de máximo esplendor ${ }^{12}$; las viñas de los selectos malvasías, irrigadas y formando cerrados emparrados, ascendían desde el litoral para ser sustituidas a determinada altitud por cepas productoras de caldos inferiores, los «vidueños». Ambos tenían sus propios mercados: los primeros, los países del noroeste europeo, especialmente Inglaterra, desde que la menor distancia y la ruina de la viticultura del Mediterráneo oriental, por el avance otomano, redujo sus compras de malvasías en el Levante. Por su parte, los «vidueños» se destinaban al mercado colonial hispano-lusitano.

El motor de esta expansión vitícola fue, pues, el capital mercantil; la demanda exterior mantuvo su ritmo de crecimiento, tirando de los precios y haciendo posible el cultivo de tierras cada vez más marginales, a pesar de las prohibiciones para proteger la calidad de los caldos y evitar la saturación del

susceptibles de esa nueva explotación, mas no por eso ha perdido el bracero, pues tanto él como su mujer e hijos tienen asegurado un buen jornal.» $R$. Ruiz Benítez de Lugo, 1904 , p. 58.

10 E. Laclau, 1978.

"La cronología de la conquista fue la siguiente: Lanzarote (1402); Fuerteventura (1402); El Hierro (1404); La Gomera (¿1404?); Gran Canaria (1478-1483); La Palma (1492-1493); Tenerife (1494-1496).

${ }_{12}$ A. M. Macías, tesis doctoral inédita, cap. XI. Para valorar en su justo término esta producción, téngase en cuenta que la isla contaba por esta fecha con una población cercana a los 30.000 habitantes, lo cual arroja una media de 500 litros de vino por persona y año (una pipa equivale a 480 litros y se divide en 40 barriles). 
mercado ${ }^{13}$; paralelamente, esta especialización obligaba a una mayor complementariedad económica regional, con el aumento de las sementeras en las áreas no aptas para las cepas ${ }^{14}$. Una mano de obra asalariada, engrosada por el fuerte incremento demográfico y por la inmigración, sustituyó a la esclavitud propia de la economía azucarera. Mercaderes holandeses e ingleses conducían los malvasías al Noroeste a cambio de manufacturas, mientras que portugueses y canarios navegaban los vidueños y la mayor parte de tales manufacturas a los mercados coloniales ${ }^{15}$.

Este modelo agrario conoció sus primeras dificultades a mediados del xvir. La independencia de Portugal y el desarrollo de su viticultura, así como el trato favorable dado a sus caldos por la «Staple Act» de 1663 para su introducción en las colonias inglesas de Norteamérica, supuso la contracción de la demanda colonial. Mientras, los mercaderes de esta nacionalidad reducían a monopolio sus intercambios, al crear en 1666 la "Compañía de Canarias». Y si un año más tarde la oposición isleña logró su supresión, no frenó el deterioro progresivo de los términos de cambio en el comercio con el Noroeste, sobre todo a partir de 1700 , cuando se acrecentó, por una parte, la competencia de los vinos de La Madeira y Oporto en este mercado y, por otra, de los caldos andaluces y catalanes en el colonial. La carencia de mercados sustitutivos para la oferta canaria, a pesar de los considerables esfuerzos de su burguesía vitícola ${ }^{16}$, condujo a un mayor protagonismo de la demanda, en manos de un número cada vez más restringido de mercaderes irlandeses e ingleses, los cuales pasaron a controlar la oferta ${ }^{17}$. Se redujo la operatividad de la dialéctica precios/producción, ni siquiera favorable para los grandes propietarios que disponían de suficiente stock y de capital para sostener el cultivo sin recurrir al préstamo, pudiendo, en su caso, esperar un cambio favorable de la coyuntura. Por supuesto, medianos y pequeños propietarios ocupaban la escala inferior en los ingresos vitícolas, hipotecados de antemano en virtud de los créditos solicitados para las «fábricas» de sus viñas.

Diversas estrategias se pusieron en práctica para superar la regresión vitícola. La más inmediata consistía en liberar la oferta del control de la demanda mediante la creación de una Compañía de Comercio con capital isleño en varios

${ }^{13}$ A. M. Macías Hernández, 1984, p. 320.

14 A. M. Macías Hernández, 1983.

15 V. Morales Lezcano, 1970, pp. 36-121; F. G. Steckley, 1980; E. Vila Vilar, 1979.

16 A. Bethencourt Massieu, 1956, pp. 216-291.

17 «no comerciando otros que ellos [los ingleses], teniendo la posesión de los pocos reales que hay, obligan al pobre paisano que no posea moneda alguna, a que se someta y vaya a cuenta de sus vinos a pedir al mercader inglés para cultivar sus viñas. En fin, los isleños vienen a quedar, ya que no esclavos de los ingleses en lo personal, a lo menos en sus haciendas*. Cítado por A. M. Macías Hernández, 1985, p. 420. Similar queja indica el administrador de la hacienda de Los Príncipes. Cfr. G. Camacho y Pérez Galdós, 1947 , p. 75 . 
momentos de la centuria y de un Montepío de vinateros en 1786, cuya función principal sería la financiación del cultivo, evitando de este modo tener que recurrir a los mercaderes extranjeros ${ }^{18}$. El fracaso de estas iniciativas reveló que el factor determinante de la regresión vitícola no residía en la retirada del capital mercantil, sino en el proceso productivo, incapaz de competir con los nuevos productores, incluso en el propio mercado interior, inundado por vinos y aguardientes catalanes y mallorquines, sobre todo en la segunda mitad de la centuria. Por supuesto, la liberación del comercio colonial agudizó aún más esta competencia y la viticultura del país solamente conoció una última etapa de efímero esplendor a fines del xvirl y principios del xIx, cuando determinados factores exógenos a su aparato productivo - guerras contra Francia e Inglaterra, napoleónicas- afectaron al de sus competidores ${ }^{19}$.

La regresión arruinó los ingresos vitícolas y generó un incremento del paro agrícola, haciendo aflorar las contradicciones de clase. La emigración, prohibida en la etapa expansiva anterior con objeto de garantizar la precisa mano de obra, se convertía ahora en el medio más a propósito para aligerar la creciente tensión social ${ }^{20}$. La clase propietaria se vio entonces impelida a buscar otras soluciones, tanto para salvaguardar el orden establecido como para paliar la caída de sus rentas. Había que operar, en definitiva, sobre el proceso productivo, reduciendo sus costes de producción, singularmente el insumo trabajo, estrategia que debía ir acompañada por un aumento de la productividad por trabajador o por una disminución del salario. Pero a lo largo del siglo xviII no hubo ninguna mejora tecnológica en la viticultura canaria, el nivel de los salarios corría paralelo al de las subsistencias y, por consiguiente, toda reducción de los costes en capital variable suponían una caída de la productividad ${ }^{21}$. Así, en la hacienda de Los Príncipes se redujo en seis puntos los gastos en salarios; pero, al propio tiempo, se produjo un hundimiento de los rendimientos vitícolas (cfr. cuadros I-II).

Era preciso, entonces, ensayar otros sistemas de explotación que permitieran a la clase propietaria asegurarse al menos un cierto nivel de ingresos sin arriesgar capital alguno hasta tanto mejorase la coyuntura, ya mediante la introducción de un nuevo cultivo - difícil alternativa para un viticultor ${ }^{2}$, máxime después de casi dos siglos de viticultura-, ya gracias a un incremento del nivel de los precios vitícolas. Una solución, ensayada en el caso de la hacienda de Los Príncipes en 1762, fue su arrendamiento por nueve años a la

16 A. Bethencourt Massieu, 1956, pp. 302-304.

19. M. Macías Hernández, «Los efectos del libre comercio sobre la economía canaria (1765-1824)w, en prensa.

20 A. M. Macías Hernández, tesis doctoral inédita, cap. XIV.

21 Ibidem, cap. VI.

22 E. Labrousse, 1973, pp. 442-443. 
casa de comercio irlandesa "Comings y Comp.», del Puerto de la Cruz, con resultados desastrosos para la plantación, según denunciaba el administrador del mayorazgo ${ }^{23}$. En realidad, la estrategia óptima se basaba en una fórmula contractual que convirtiera los gastos de explotación, prácticamente fijos, en variables, de acuerdo con el nivel de la producción anual, de la demanda y de los precios, sin que ello suponga una disminución de los rendimientos y de la productividad de la mano de obra. En definitiva, un contrato en el que el 70 por 100 de los costes de producción fueran una función del ingreso, y tal tipo de relación contractual no es otra que la medianería. Como ha demostrado J. D. Reid a partir de una reelaboración de la teoría neoclásica, aludiendo a una situación agraria bajo las características citadas, la clase propietaria desplazará la gestión directa por la medianería desde el momento en que la producción marginal del medianero sea inferior al coste salarial ${ }^{24}$. Por su parte, el regidor J. de Llarena y Mesa, futuro marqués de Casa Hermosa, en junta del Cabildo de Tenerife de julio de 1777 , convocada para protestar por la introducción de vinos y aguardientes peninsulares, sintetizaba de este modo las circunstancias que rodeaban el cambio en el sistema de explotación:

es constante... que las viñas en lo general se hallan mui deterioradas e imposibilitados sus dueños de ponerlas en buen estado por falta de caudales, e respecto a que su principal ruina depende de su demasiada antigüedad, siendo evidente que las más de las haciendas tienen de plantadas un siglo, uno y medio y aun dos y necesitan deseparse, dejar descansar la tierra algunos años y plantarlas de nuebo, impensas que no pueden sufragar los mayores hacendados a quienes con escasez les rinden sus maiorazgos para el presiso mantenimiento de sus familias, aun en aquellos años que logran vender sus frutos con tal o qual estimasión, de que dimana verse muchísimos en la presisión de dar sus hasiendas a partido de medias, recogiendo el medianero la mitad íntegra de los frutos por haver suplido las labores; que también es constante que son de algunos años a esta parte más costosas las fábricas de las viñas, por la aniquilación de los montes y la falta de jornaleros, siendo preciso pagarles la mitad más del estipendio ordinario en las fábricas que no admiten demora, al mismo tiempo

${ }^{23}$ «Vuestra Excelencia ha vivido engañado. Las Haziendas destas islas que son de cultivo no pueden arrendarse sin quebranto $y$ atraso de sus dueños. Pueden arrendarse el molino, el tributo, la huerta, la propiedad de panificar sin riego, la casa, pero ninguna otra cosa; las viñas se pierden absolutamente en arrendamiento porque aquel que no le duele ni mira a otra cosa que a sacarle el jugo se le da poco que se pierda el otro año.» Citado por G. Camacho y Pérez Galdós, 1947, pp. 25-26.

${ }^{24}$ J. D. Reid, 1976, pp. 553-554. 
que se nota aumento de presio en las ropas y comestibles; de suerte que aquellos mismos maiorazgos que mantenían con esplendor a sus poseedores en el siglo pasado... años ha que no dan para la desente manutensión y para poder fabricarlos 25 .

\section{LA CUANTIFICACION DEL CAMBIO EN LOS SISTEMAS DE EXPLOTACION}

La verificación de esta estrategia requiere la consulta de la contabilidad agrícola de un número representativo de explotaciones, combinando el estudio de una gran hacienda con el de minúsculas parcelas ${ }^{26}$, exigencia metodológica no siempre posible ${ }^{27}$. En nuestro caso, el análisis se fundamenta en la contabilidad de seis explotaciones cuya representatividad no ofrece duda alguna. Situadas en el valle de La Orotava (Tenerife), primera zona vitícola de la isla y del Archipiélago ${ }^{28}$, la primera, denominada hacienda de Los Príncipes, constituye una gran explotación perteneciente al extenso y rico mayorazgo fundado en 1520 por el conquistador de la isla, Alonso Fernández de Lugo ${ }^{29}$. Su superficie propiamente vitícola era de 78 hectáreas y 33,0765 áreas en un único cuerpo, si bien dividido en tres grandes parcelas o cercados, de 94,5, 23,25 y 31,5 fanegadas, respectivamente ${ }^{30}$. Valorada en 850.995 reales en 1844 , es decir, a $5.701,8$ rs. por fanegada en el período de decadencia vitícola,

${ }^{25}$ Archivo Municipal de La Laguna, Libros de Acuerdos del Cabildo, lib. 27, of. 1, fol. 185.

${ }^{26}$ P. Vilar, 1962, II, p. 419.

27 La relativa cercanía de los propietarios a sus haciendas hacía innecesaria una adecuada práctica contable; llevaban directamente la gestión de sus explotaciones y en contadas ocasiones anotaban sus resultados, tratándose entonces de diarios más o menos completos en los que no es fácil distinguir los ingresos y gastos propios de la explotación. La documentación contable utilizada constituye una excepción, debida, en el caso del mayorazgo de los Adelantados, a que sus propietarios residían en la Península, quedando el fundo en manos de un administrador. En otros se debe a la intervención de la Hacienda o a la profesión mercantil de su propietario. Solamente en el caso de J. de Urtusaustegui, aunque no con todo rigor, puede hablarse de una gestión contable encaminada a precisar los costes de explotación con el fin de maximizar el beneficio.

2 A. M. Macías Hernández, tesis doctoral inédita, cap. XI. La producción vitícola del valle de La Orotava representaba aproximadamente el 52 por 100 del total insular, mientras que la isla aportaba el 75 por 100 al total regional en el siglo XvirI.

${ }^{29} \mathrm{G}$. Camacho y Pérez Galdós, 1944, pp. 11-18. Durante el período que nos ocupa, el mayorazgo estaba en poder de la casa de los condes de Torralba.

${ }^{30}$ Archivo de la Hacienda de Los Príncipes, Estado de las tierras y rentas del mayorazgo de Los Principes en 1844, leg. sin clasificar. Otra de sus valoraciones, realizada en 1734, computaba el capital fijo de la hacienda en siete lagares y su correspondiente bodega, con 265 pipas, 25 picones, 25 barras, 2 marrones, 2 azadas y 2 rozaderas; cuatro casas para los respectivos mayordomos, caballerizas, graneros y las casas principales. La fanegada de Tenerife equivale a $5.248,29$ metros cuadrados. 
se extendía en dirección mar-cumbre, alcanzando superior cotización las tierras más bajas, a 6.017 rs. por fanegada, debido a su mayor productividad y a la mejor calidad de sus caldos.

En este sentido, la explotación era modélica: producía por término medio un 75 por 100 de selectos malvasías con destino al mercado inglés, mientras que el 25 por 100 restante, de vino vidueño, se comercializaba en las ventas de la localidad, enviándose alguna partida a Indias, transformada a veces en aguardiente, y, sobre todo, era empleado como un componente más del salario en las labores del cultivo. Por consiguiente, dada la superficie media de las explotaciones en Canarias, estimada a mediados del xIx entre 7,7-12,8 hectáreas para la mediana y gran propiedad ${ }^{31}$, y la elevada proporción de caldos de superior calidad en su producción, Los Príncipes constituyen un ejemplo excepcional de gran explotación vitícola (cfr. cuadros I-II).

El conde del Valle de Salazar poseía dos explotaciones, en El Sauzal y Zamora, pago éste de La Orotava ${ }^{32}$. Y aunque carecemos de información sobre su equipamiento, distribución de cultivos y superficie, además de que sus cuentas se presentan de forma agregada, tales inconvenientes no son obstáculo para señalar, mediante el examen de la tipología de sus gastos, que disponían de albercones para su riego, bodegas, lagares, casas para los mayordomos, etc.; los malvasías constituían más del 80 por 100 de su producción (cfr. cuadro III), y considerando, por ello, que los rendimientos medios de ambas explotaciones fueran similares a los alcanzados en la anterior hacienda, su superficie global estimada sería de unas 35,6 fanegadas ${ }^{33}$.

La casa de comercio Cologan, del Puerto de la Cruz, dedicada prioritariamente a la actividad mercantil con Europa y América ${ }^{34}$, era propietaria de pequeñas haciendas vitícolas diseminadas por el valle. Tampoco conocemos sus extensiones y equipamientos; pero tomando como norma los rendimientos de la hacienda de Los Príncipes, la finca denominada San Diego, situada en la franja costera y de mejores caldos, podría tener una superficie media próxima a las 23,5 fanegadas, mientras que la llamada La Isleta, en el pago de Higa, a mayor altitud y de peores vinos, unas 13,3 fanegadas ${ }^{35}$ (cfr. cuadros IV-V). Finalmente, el rico propietario e ilustrado J. de Urtusaustegui poseía una importante propiedad vitícola en el citado pago de Zamora, cuya

"J. del Moral Ruiz, 1979,.p. 119.

2 Conocemos su contabilidad por el hecho de que las propiedades del conde estuvieron intervenidas por su participación en la guerra de Sucesión al lado del archiduque.

${ }_{33}$ Resultado de dividir la media de las cosechas de $1700-07$ y $1712-17$ por un rendimiento medio de 15,6 barriles por fanegada, obtenido en la hacienda de Los Príncipes en el trienio 1772-75.

4 A. Guimerá Ravina, 1985.

${ }^{35}$ Se ha calculado tomando como dividendo las cosechas obtenidas en régimen de medianería. 
contabilidad permite precisar la evolución de la viticultura en el período 1790 1814 , su última fase de efímero esplendor. Ignoramos su superficie, pero su mejor explotación, cultivada en régimen directo, se aproximaba a las 13,6 fanegadas, mientras que el resto de igual extensión se dividia en varios cercados cedidos a medianería (cfr. cuadros VI-VIII) ${ }^{36}$.

\subsection{Los ingresos del propietario}

El descenso de los ingresos de la hacienda de Los Príncipes en el último decenio del siglo xvir, explotada en régimen de medianería, determinó a su nuevo propietario, el conde de Torralba, pasar a la gestión directa, olvidando verificar que el problema no radicaba en una disminución del nivel de productividad del colonato, sino, fundamentalmente, en la caída de los precios del malvasía (cfr. cuadro I). La iniciativa del conde no se vio coronada por el éxito; si los ingresos netos del quinquenio 1695-1696/1699-1700 ascendieron a $2.866 .775 \mathrm{mrs}$., en el trienio $1707-1709$ se redujeron en un 35,2 por 100. Por su parte, este decremento fue del 66,8 por 100 en el caso de las fincas del conde del Valle de Salazar entre 1700 y 1717 (cfr. cuadro III), siendo muy probable la continuidad de esta tendencia, por cuanto la comparación de los ingresos netos de la hacienda de Los Príncipes del trienio 17071709 con los del quinquenio $1734-1738$ permite comprobar una reducción del 97 por 100; siguieron luego varios años de balances negativos, agravados por la guerra con Inglaterra, con una relativa recuperación en el decenio 17461755 , concretamente en los años 1749, 1752 y 1755.

Las dos haciendas de la casa de comercio Cologan también conocieron la regresión: sus ingresos medios en el quinquenio 1747-1751 fueron negativos; se recuperaron en el quinquenio siguiente, y sobre todo en el tercero (17571761) en el caso de la hacienda de S. Diego - la de La Isleta se dio a medias-, para luego conocer una fase de estancamiento. En definitiva, los ingresos netos de las haciendas examinadas muestran una clara reducción de su cuantía desde comienzos de la centuria, con su punto más bajo en la década de 1740; diez años más tarde se inició una recuperación, interrumpida después de 1761 1762. Los únicos años de mejores cotizaciones en las explotaciones analizadas se sitúan entre 1748-1749 y 1761-1762 para el vino malvasía, es decir, en la fase interbélica con Inglaterra, su tradicional mercado ${ }^{37}$.

Frente a este decremento de la demanda y de los precios, los gastos de explotación, en los que las labores de cultivo representaban por término medio

* Dividendo: en el primer caso, media de las cosechas de 1795-98, 1799-1803, 18031807 y de 1808-10; en el segundo, de 1798-1802, 1803-07 y 1808-11.

3 A. M. Macías Hernández, 1984, p. 320. 
un 70 por 100 del total invertido, debían permanecer constantes para no poner en peligro el nivel de productividad. Una relativa autarquía interna, basada en una elevada complementariedad de las unidades productivas, permitía a su clase propietaria ejercer un relativo control sobre el salario, pagando, aproximadamente, un 51,4 por 100 de su valor nominal en especie. Dicha proporción se descomponía, a su vez, en vino, trigo $(21,6$ por 100 , respectivamente) y pescado salado $(8,2$ por 100$)$, siendo ésta la única partida adquirida por el propietario ${ }^{38}$.

Pero la proporción del salario abonado en especie comenzó a ser más cara a medida que sus precios iniciaron un movimiento alcista, a partir de 1765 , con la liberación del mercado interno. De ahí el incremento de los gastos de explotación en aquellas haciendas cuyos propietarios carecían de la citada complementariedad económica, mientras que los que se encontraban en esta situación podían mejorar el coste de oportunidad del trigo empleado en las labores conduciéndole al mercado. Ahora bien, tal cambio suponía una modificación de la estructura salarial nada favorable para la clase propietaria, por cuanto perdía su capacidad de intervenir en el salario, frenando su tendencia al alza o valorando su proporción en especie por encima de los precios de mercado, o bien, finalmente, reduciendo su participación en dicha estructura salarial ${ }^{39}$. No obstante, estos mecanismos hallaron un clima laboral menos propenso a su actuación en la segunda mitad de la centuria. La emigración reducía el nivel de saturación del mercado de trabajo, permitiendo a los jornaleros vitícolas la obtención de un mejor nivel de contratación, sobre todo en los momentos de mayor demanda de fuerza de trabajo ${ }^{40}$.

En definitiva, la escasa capacidad de la clase propietaria para controlar en su beneficio los costes de transacción, elevándose considerablemente la incidencia del riesgo, convertía a la gestión directa en una alternativa irrentable, mientras que el arrendamiento atentaba contra la propia supervivencia de la explotación. El régimen de tenencia óptimo en estas circunstancias era la medianería, ensayada ya en el caso de la hacienda de Los Príncipes a fines del xvir: a cambio de la mitad de la cosecha, recogida en la vica del lagar, el colono costeaba prácticamente todos los gastos de explotación, es decir, el 70 por 100 del total invertido. Por supuesto, el medianero corría también con la mitad de los costes de lagares, pipas y bodegas, relativos a su participación

34 Componente también del salario eran las ropas extranjeras, intercambiadas por la clase propietaria con los mercaderes a cambio de los caldos. En los casos examinados, la participación de las ropas extranjeras variaba desde un 16,1 hasta un 50 por 100 . En cierto sentido y en una extensión todavía difícil de valorar, nos hallamos con ejemplos de un peonaje sujeto por deudas. Cfr. A. M. Macías Hernández, tesis doctoral citada, cap. XIV.

Is Ibidem.

* Cfr. nota 27. 
en la cosecha. Los únicos gastos realizados por el propietario eran aquellos que quedaban a beneficio de la explotación, relacionados con su capital fijo. No obstante, en toda inversión que significase una mutua ventaja para colono y propietario, como la limpieza de canales de riego o estanques, los primeros quedaban obligados acudir a dicho trabajo, recibiendo como estipendio solamente su manutención en los días que durase la labor ${ }^{41}$.

Con el cambio en el régimen de explotación, los ingresos netos de las haciendas analizadas aumentaron considerablemente. En el caso de la de Los Príncipes subieron de una media de $111.395 \mathrm{mrs}$. de Canarias en el quinquenio $1751-1755$ a 1.337 .072 en el trienio $1772-1774$ (cfr. cuadro I); por su parte, en la hacienda de La Isleta, de la casa de comercio Cologan, aumentaron en un 280 por 100 (cfr. cuadro V). Ahora bien, hemos computado estrictamente los ingresos vitícolas cuando la relación contractual permitía una mayor maximización de la renta mediante la aplicación de sus dos variantes. En la primera el propietario se limitaba a comercializar su parte de cosecha, absteniéndose de adelantar capitales al medianero a cambio de su participación, circunstancia que obligaba a éste, en el supuesto bastante probable de no disponer de un fondo de ahorro, a obligar aquélla a los mercaderes extranjeros a cambio de su ayuda financiera ${ }^{42}$. Pero en este caso la producción de cereal, millo, papas, de los predios anexos a la explotación vitícola, destinada a sufragar la parte del salario computada en especie en la gestión directa, es ahora totalmente comercializada por el propietario, vendida al precio de mercado a los mismos medianeros y/o a otros compradores.

La segunda variante contractual otorgaba a la clase propietaria mayores beneficios, siendo la más generalizada en la viticultura canaria. Se trataba de comercializar la parte de cosecha correspondiente a los medianeros, adelantándole los capitales necesarios para la reproducción de la unidad productiva y generando, de este modo, un campesinado sujeto por deudas ${ }^{43}$. Con ello la burguesía vitícola lograba reducir el control ejercido por la demanda exterior, en manos de mercaderes extranjeros, aumentando su stock y su capacidad de

" En el contrato también se estipulaba la colaboración de los medianeros y de sus animales de labor en aquellas faenas que estimase el propietario, no recibiendo por ello estipendio alguno.

${ }_{72}$ Una de las contestaciones en contra del proyecto del Montepio de vinatęros se basaba en que no era necesario el mismo por cuanto éstos podían obtener los capitales para las fábricas de sus viñas recurriendo a los mercaderes extranjeros. A. M. Macías Hernández, 1978, p. 37.

${ }^{43}$ H. K. Takahashi, 1972, pp. 79-80. Refiere una situación similar en la agricultura francesa, citando a Arthur Young. Igual referencia podemos emplear para el caso canario, debida a A. Humbolt: *en general, los cultivadores no son propietarios; el producto de su trabajo pertenece a la nobleza y las mismas instituciones feudales que han mantenido tanto tiempo a toda Europa en la miseria, siguen poniendo trabas a la felicidad del pueblo en las islas Canarias*. Citado por A. M. Macias Hernández, 1985, p. 426. 
negociación y evitando la atomización de la oferta, en manos de medianeros hipotecados a la clase mercantil; esta reducción de los mecanismos de intervención de esta última en el proceso productivo, alejándola lo más posible del mismo, permitia a aquélla poder apropiarse de la diferencia existente entre los precios en origen y los vigentes en el puerto exportador; maximizar el empleo de su capital fijo - lagares, bodegas, pipas-, el cual, de otro modo, quedaba reducido a la mitad de su potencial. Finalmente, los adelantos a la unidad productiva consistían en productos manufacturados y agrarios, componentes anteriores del salario y que, vendidos ahora a precios de mercado, suponían también una participación directa en las ganancias generadas por el mercado interior.

Conocemos los ingresos derivados de la práctica de esta modalidad contractual para fines del xvir y xviII. En el caso de la hacienda de Los Príncipes, su administrador adquirió el mosto de sus medianeros, a 754,3 mrs. el malvasía y a $394,3 \mathrm{mrs}$. el vidueño; ambas calidades alcanzaron, a los tres meses aproximadamente, un precio medio de $1.833,6$ y $1.115,5$ mrs., respectivamente (cfr. cuadro VII). En conjunto, considerando los gastos generales invertidos por el administrador en el encierro del mosto de los medianeros, la hacienda obtuvo un beneficio que osciló entre un 75-100 por $100^{4}$. Por su parte, J. de Urtusaustegui realizaba también esta variante contractual. $Y$, aunque no conocemos la cuantía de los gastos efectuados, la diferencia entre el precio del mosto en origen, es decir, a la vica del lagar, y el precio del vino fue más del doble (cfr. cuadro VIII).

Ahora bien, este propietario también comparaba los ingresos derivados de la gestión directa y de la medianería para conocer indudablemente el momento propicio de su sustitución por el primer régimen de explotación. Y éste llegó a fines de la centuria, con el incremento de la demanda exterior y de los precios ${ }^{45}$. Despidió a los medianeros de sus parcelas más fértiles para cultivarlas directamente y reforzó los lazos de dependencia económica con el resto de los medianeros con objeto de asegurarse una mano de obra complementaria en determinadas faenas agrícolas ${ }^{46}$. Así, frente al hundimiento de los ingresos en régimen directo de la hacienda de Los Príncipes y de los mejores índices de la finca de S. Diego, de Cologan, ahora la «cuota de beneficio» no cesó

* Téngase en cuenta que aquí el cálculo del beneficio no es todo lo correcto que sería de desear, habida cuenta de que no disponemos de una valoración del capital fijo de las explotaciones ni de otras consideraciones para poder obtener su perfecto cómputo. Debe, pues, aceptarse con estas reservas.

4s. M. Macias Hernández, 1984, p. 320.

* En efecto, los nuevos contratos de medianería obligaban por un salario establecido en la propia relación contractual, redactada para uso interno del propietario y no ante escribano, a cooperar en las faenas de riego, vendimia y cava. Archivo Lugo Massieu, Diario de cuentas de Juan de Urtusaustegui, s. c. 
de crecer entre 1796 y 1810 , alcanzando la cota del $270-300$ por 100 , y probablemente, la tendencia continuó hasta 1814, fecha del cambio de coyuntura, ahora depresiva, de los precios vitícolas (cfr. cuadro VI).

\subsection{Los ingresos del medianero viticultor}

La productividad, medida por los rendimientos de la explotación y del capital invertido, constituye la variable determinante de los ingresos del medianero viticultor, actuando de forma secundaria, al menos a corto plazo, el nivel de precios ${ }^{47}$. Por supuesto, la clase propietaria es parte interesada en esta productividad, dado que la cuantía de su participación en el producto de la explotación depende de la cosecha obtenida, y de ahí que vigile estrechamente los rendimientos; en caso de desacuerdo con el colono, el desahucio era inmediato, sin existir protección jurídica alguna para este último ${ }^{40}$. Los años de mayores rendimientos por hectárea en la hacienda de Los Príncipes y de La Isleta se dieron bajo el régimen de medianería: de unos 6,1-7,6 $\mathrm{Hl}$. en gestión directa, cifra enormemente baja y que revela el abandono a que había llegado el cultivo en la primera hacienda, dadas las expectativas del mercado, se pasa a unos rendimientos medios de casi el doble, a 11,9 $\mathrm{Hl}$. por hectárea. La productividad del capital invertido por los medianeros era también más elevada: mientras el coste medio de las labores en la medianería oscilaba entre los 200-400 mrs. por barril, en la gestión directa se situaban entre los 800 $1.000 \mathrm{mrs}$. En definitiva, el medianero obtenía mayores rendimientos con menores dosis de capital, en cuyo ahorro también se cifraba, por otra parte, su nivel de ingresos.

Ahora bien, esta mayor productividad es ilusoria, por cuanto oculta la utilización de una fuerza de trabajo no computada y remunerada como tal en los costes de explotación efectuados por el medianero: la mano de obra familiar, de una familia extensa, y, en segundo lugar, la generada por el cooperativismo campesino. Ambas características de la fuerza de trabajo en el régimen de aparcería eran auspiciadas por la clase propietaria. En las fincas analizadas, la mayoría de los medianeros estaban unidos por lazos de parentesco, los cuales actuaban en favor de una reproducción del régimen contractual, dado que el propietario reclutaba los nuevos colonos entre los hijos y parientes de los

4 E. Labrousse, 1973, pp. 222-223.

* Las disposiciones limitativas del desahucio del colonato, sobre todo la Real Cédula de 8 de septiembre de 1794, no tenían aplicación alguna en el caso de que se tratase de medianeros, según argumentaba la clase propietaria. A. M. Macías Hernández, tesis doctoral citada, cap. XIV. 
ya establecidos ${ }^{49}$. Un segundo requisito se les exigía para el acceso a la medianería: contar con una familia numerosa. Con ello se lograba dar una mayor cohesión a los motivos económicos y extraeconómicos que originaban el cooperativismo campesino entre las diversas familias medianeras. Para una mayor efectividad de esta estrategia, la clase propietaria dividía la explotación entre un número adecuado de medianeros; la hacienda de Los Príncipes contaba por término medio 22 aparceros, con una media de 6,7 fanegadas de viñedo ${ }^{50}$. De esta forma, se trataba de un colonato «cuasi proletario", al cual se le entregaba una pequeña parcela de acuerdo con su disponibilidad de fuerza de trabajo y no de capital; su solicitud financiera, al propietario del fundo o al mercader extranjero, cumplía la finalidad de reproducir esta mano de obra a lo largo del año agrícola. Se deduce entonces que los ingresos del medianero dependían de que la demanda de trabajo de la explotación fuera cubierta en la medida más elevada posible por la unidad familiar y por el cooperativismo campesino en los períodos de las grandes faenas agrícolas. Además, esta tendencia al ahorro de todo coste monetario suponía también limitar sus relaciones de dependencia económica de la clase propietaria o mercantil.

En definitiva, los ingresos del medianero viticultor, como oferente en último término de fuerza de trabajo, estaban determinados por su nivel de productividad. Ciertamente, las alzas cíclicas anuales de los precios tenían también su incidencia, por cuanto suponían un estímulo a la obtención de mayores rendimientos, invirtiendo incluso más trabajo en la explotación, proceso que conducía finalmente a un aumento de sus beneficios. Pero, como hemos verificado anteriormente, en el caso de que se produjera una tendencia alcista a medio plazo de los precios, de tal manera que el valor monetario de la parte de cosecha correspondiente al medianero fuera superior a los gastos de cultivo que tuviera que costear el propietario, se le ofrecía a este último la posibilidad de sustituir al colono por el asalariado.

Los ingresos del medianero viticultor constituían, por consiguiente, una renta salarial estrechamente ligada a su nivel de productividad. Ahora bien, dichos ingresos netos en las explotaciones analizadas no llegaban a cubrir el ingreso teórico anual de un jornalero viticultor. En efecto, suponiendo una jornada laboral anual de 220 días, su renta salarial ascendería a $31.680 \mathrm{mrs}$., cifra que no alcanzaron los ingresos de los medianeros de la hacienda de Los Príncipes en los dos quinquenios examinados del siglo xviI, sino en dos ocasiones. Considerando el ejemplo de otra explotación bajo idéntica modalidad

99 Esta estrategia de la clase propietaria se mantuvo hasta fechas recientes en el agro isleño. Cfr. A. Galván Tudela, 1980, pp. 205-227.

${ }^{30}$ A. M. Macías Hernández, tesis doctoral citada, cap. XIV. En otras fincas analizadas, la dimensión media de los predios de viñedo entregados en aparcería oscilaban entre 4 y 6 fanegadas. 
contractual, es decir, con la comercialización de la cosecha obligada al propietario y para los años finales del xviII, etapa caracterizada por una efímera recuperación y crecimiento vitícola, las conclusiones son similares. Así, pues, y teniendo en cuenta las características de la fuerza de trabajo en la medianería, no computada en su mayor parte en los gastos de cultivo, debe concluirse indicando la existencia de una auténtica sobreexplotación del colonato sometido a este régimen contractual.

Cabe entonces preguntarse, finalmente, por las razones que determinaron su aceptación. En este sentido, habría que valorar, primeramente, la reducción de las expectativas de empleo y la saturación del mercado de trabajo como consecuencia de la regresión vitícola y de la generalización del propio contrato de medias ${ }^{51}$. Ante esta situación, los jornaleros solamente podían optar por dos alternativas: desplazarse a las áreas de policultivo y roturar clandestinamente las tierras baldías de dominio realengo, encontrando así una posibilidad de empleo en este subsector agrario en expansión ante el crecimiento de los precios del cereal. Mas esta posibilidad se hallaba limitada por la propia asignación jurídica del disfrute de los terrenos baldíos realengos, los cuales funcionaban como bienes comunales; se requería estar avecindado en su comunidad respectiva, lo cual restringía el empleo de este recurso a su vecindario ${ }^{52}$. Otra opción, más arriesgada, consistía en la emigración a América, elegida a pesar de ello por un número creciente de isleños, y de ahí las quejas de la burguesía vitícola por la falta de mano de obra y la presión alcista de los salarios ${ }^{53}$. Pero, como hemos indicado, el medianero viticultor era miembro de una numerosa familia; obligaciones familiares, edad ya madura y, en algunos casos, el contar con algún pequeño predio en propiedad limitaban la alternativa migratoria para la inmensa mayoría de los medianeros.

Ahora bien, en el contexto descrito, el acceso a este status contractual constituía un auténtico privilegio. Si anteriormente hemos comparado los ingresos del jornalero vitícola con los de su homónimo medianero para valorar su nivel de sobreexplotación, hemos dado por supuesto que el primero contaba con una renta salarial anual estable, y esta posibilidad era pura teoría en las circunstancias concretas del mercado de trabajo. Por su parte, la medianería significaba disponer de una parcela donde obtener al menos la subsistencia, ampliaba sus posibilidades económicas en el caso de que el colono fuera propietario minifundista y, si bien los ingresos netos de su participación en la cosecha eran menores que una renta salarial teórica anual, tenía la oportunidad de plantar en las cortinas de la explotación algunos cultivos para su consumo y/o

si Ibidem.

32 Ibidem, cap. XIII. Se trata de una situación similar a la vigente en Castilla sobre el uso de la propiedad comunitaria. D. E. Vassberg, 1986, pp. 83-86.

${ }^{33}$ Cfr. nota 25. 
para alimentar un pequeño hato de ganado menor. Tales cultivos y ganado aseguraban, en definitiva, la reproducción de la familia medianera, y de esta forma los citados ingresos netos suponian solamente un aporte monetario en los contados años en los que su coste de reproducción fuera inferior a los adelantos exigidos para costear los gastos de explotación.

\section{BIBLIOGRAFIA}

Bet h encourt Massieu, A. (1956): «Canarias e Inglaterra: el comercio de vinos (1650 1800)», en Anuario de Estudios Atlánticos, núm. 2, pp. 195-308.

Bingroli, G. (1979): «I problemi dell'economia toscana e della mezzadria nella prima metà dell'Ottocento», en Contadivi e propietari nella Toscana moderna, Florencia, Leo S. Olschki, vol. 1, pp. 85-172.

BLOCH, M. (1978): La bistoria rural francesa: caracteres originales, Barcelona, Crítica.

Brres, T. J. (1983): «Historical Perspectives on Sharecropping», en The Journal Peasant Studies, núms. 2-3, pp. 7-41.

Caballero, J. M. (1983): «Sharecropping as an Efficient System: Further Answers to an Old Puzzle», en The Journal Peasant Studies, núms. 2-3, pp. 107-119.

Camach o y Pérez Galdós, G. (1947): La Hacienda de Los Príncipes, La Laguna, Instituto de Estudios Canarios.

Catrini, M. (1978): *In Emilia Orientale: mezzadria cinquecentesca e mezzadria settecentesca. Continuità o frattura?», en Quaderni Storici, núm. 39, pp. 864-881.

Cherubinr, G. (1979): «La mezzadria toscana delle origini», en Contadini e propietari nella Toscana moderna, vol. 2, pp. 132-152.

Galván Tudela, A. (1980): Taganana. Un estudio antropológico social, Santa Cruz de Tenerife, Aula de Cultura del Cabildo de Tenerife.

GuImerá RAvina, A. (1985): Burguesía extranjera y comercio atlántico. La empresa comercial irlandesa en Canarias (1703-1771), Santa Cruz de Tenerife, Consejería de Cultura y Deportes del Gobierno de Canarias/CSIC.

Labrousse, E. (1973): Fluctuaciones económicas e bistoria social, Madrid, Tecnos.

LACLAU, E. (1973): «Feudalismo y capitalismo en América Latina*, en Tres ensayos sobre América Latina, Barcelona, Anagrama, pp. 43-89.

Macf́as Hernández, A. M. (1978): La transformación de la propiedad agraria concejil en el paso del antiguo al nuevo régimen, La Laguna, Anexo 1 de la Revista de Historia Canaria.

- (1983): «La producción de cereales en Canarias: el ejemplo del trigo (1610-1820)», en Congreso de Historia Rural. Siglos XV al XIX, Madrid, Universidad Complutense.

- (1984): *Canarias en la Edad Moderna*, en Historia de los Pueblos de España. Tierras fronterizas. I. Andalucía. Canarias, Barcelona, Argos Vergara, pp. 312-341.

- (1985): «Canarias en el siglo XVIII: una sociedad en crisis», en R. FERNÁndez (ed.): España en el siglo XVIII. Homenaje a Pierre Vilar, Barcelona, Crítica, pp. 413-433.

Malamina, P. (1979): «La propietà fiorentina e la diffusione della mezzadria nel contado pisano nei secoli XV e Xvi», en Contadini e propietari nella Toscana moderna, vol. 2, pp. $345-376$.

Mande, J. R. (1983): «Sharecropping and the Plantation Economy in the United States South», en The Journal of Peasant Studies, núms. 2-3, pp. 120-129.

Marx, C. (1981): El capital, Madrid, Siglo XXI. 
Moral Ruiz, J. (1979): La agricultura española a mediados del siglo XIX, 1850-1870, Madrid, Instituto de Estudios Fiscales.

Morales Lezcano, V. (1970): Relaciones mercantiles entre Inglaterra y los Archipiélagos del Atlántico Ibérico. Su estructura y su bistoria (1503-1783), Santa Cruz de Tenerife, Instituto de Estudios Canarios.

Penrce, R. (1983): «Sharecropping: Towards a Marxist View, en The Journal of Peasant Studies, núms. 2-3, pp. $42-70$.

Peraza de Ayala, J. (1955): «El contrato agrario y los censos en Canarias», en Anuario de Historia del Derecho Español, vol. XXV, pp. 257-301.

ReID, J. D. (1976): «Sharecropping and Agricultural Uncertainty», en Economic Development and Cultural Change, núm. 3, pp. 549-576.

RoBertson, A. F. (1980): "On sharecropping*, en Man (n. s.), núm. 15, pp. 411-412.

Ruiz Benftez De Lugo, R. (1904): Estudio sociológico y económico de las Islas Canarias, Madrid.

STECKLEY, F. G. (1980): *The Wine Economy of Tenerife in the Seventeenth Century: Anglo-Spanish Partnership in a Luxury Trade», en Economic History Review, núm. 3, pp. 335-350.

StolCKE, V., y Hall, M. M. (1983): *The Introduction of Free Labour on São Paulo Coffee Plantationsw, en The Journal of Peasant Studies, núms. 2-3, pp. 170-200.

TAkA н AS I, H. K. (1972): «Contribución al debate*, en La transición del feudalismo al capitalismo, Barcelona, Artiach, pp. 65-106.

Vassberg, D. E. (1986): Tierra y sociedad en Castilla, Barcelona, Crítica.

VILA VILAR, E. (1979): «Las Canarias como base de aprovisionamiento de navíos portugueses*, en II Coloquio de Historia Canario-Americana, Sevilla, Ed. del Cabildo Insular de Gran Canaria.

Vilar, P. (1962): La Catalogne dans l'Espagne moderne. Recberches sur les fondeménts économiques des structures nationales, París, 3 vols.

WAllersteIN, I. (1979): El moderno sistema mundial. La agricultura capitalista y los orígenes de la economia-mundo europea en el siglo XVI, Madrid, Siglo XXI. 


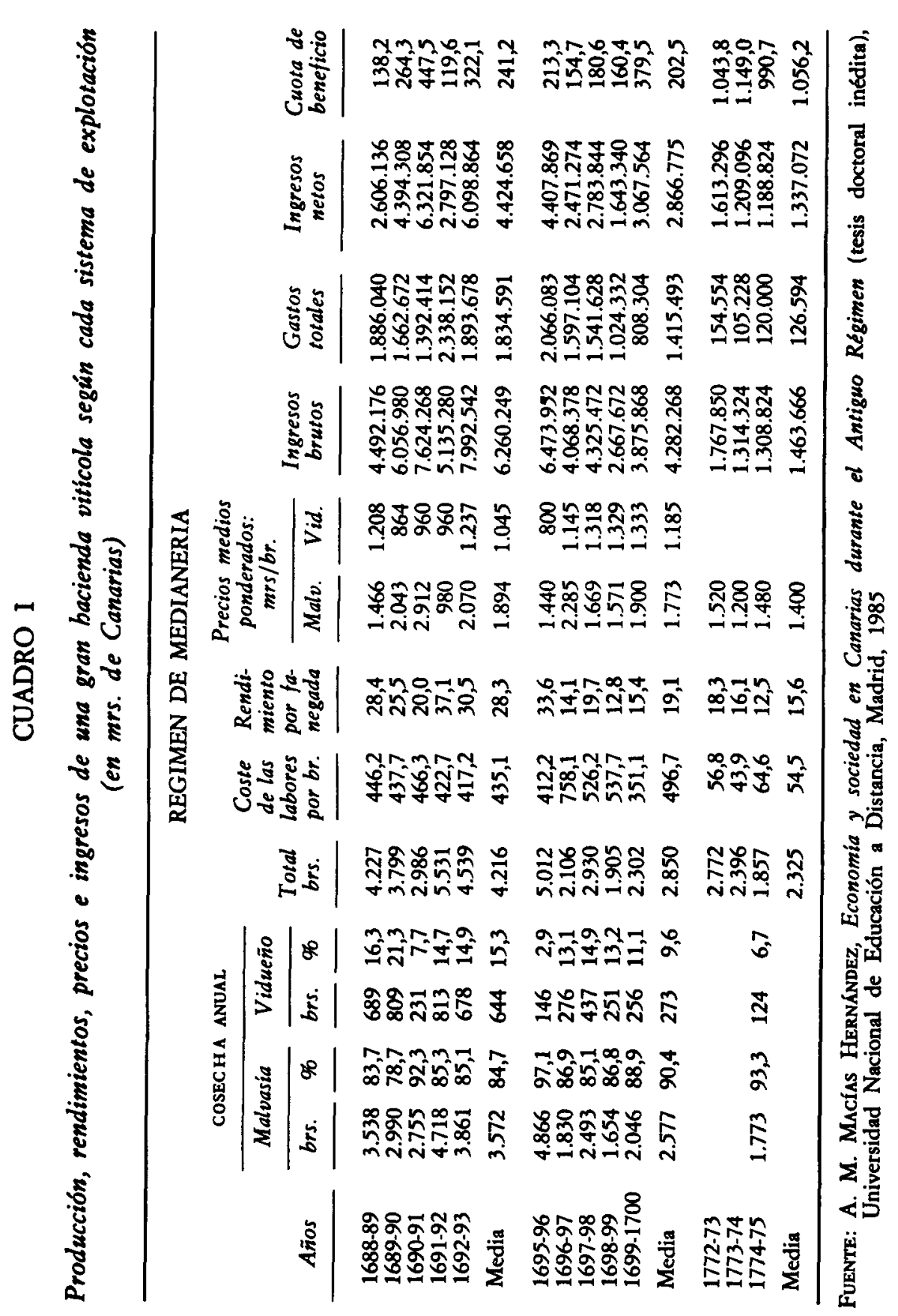


茟

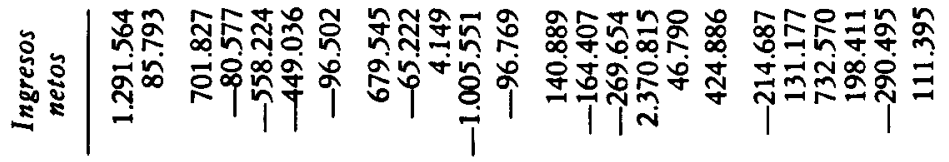

气

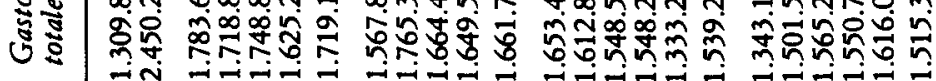

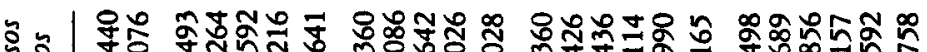
इ

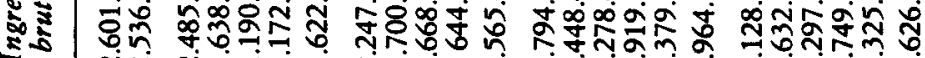
نN

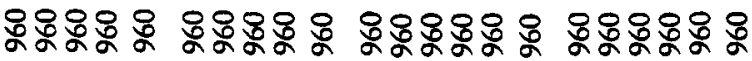

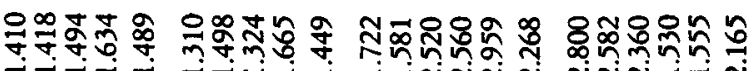

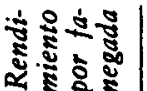

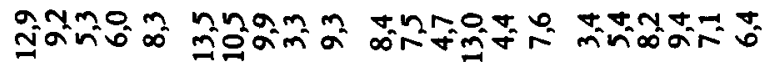

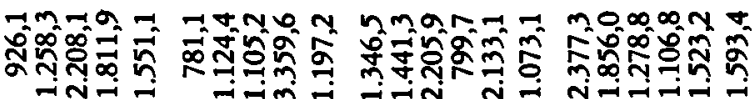
จุ๊

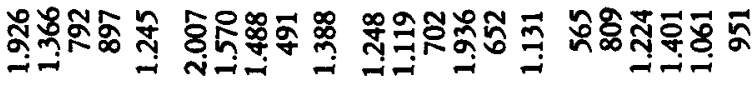

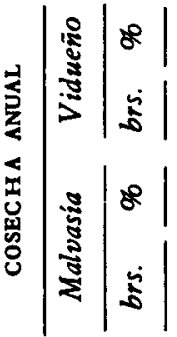

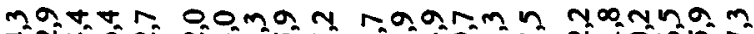

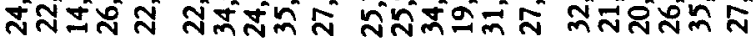

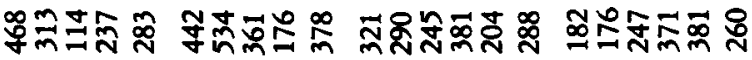

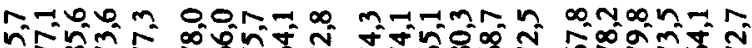
ที⿰氵丶犬木

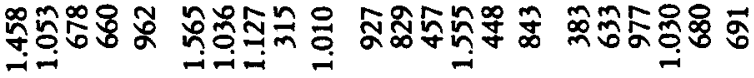

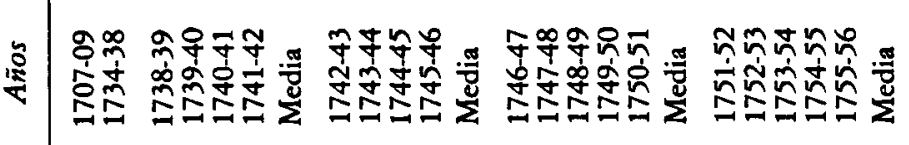




\section{CUADRO II}

Estructura de los gastos realizados por el propietario en la gestión directa y en la medianería: caso de la bacienda de Los Príncipes

\begin{tabular}{|c|c|c|c|c|c|c|c|c|c|}
\hline \multirow[b]{3}{*}{ Años } & \multirow{2}{*}{\multicolumn{6}{|c|}{$\begin{array}{l}\text { REGIMEN DE MEDIANERIA } \\
\text { STOS DE EXPLOTACION }\end{array}$}} & \multirow{3}{*}{$\begin{array}{c}\text { Compra } \\
\text { cosecha } \\
\text { medlanero }\end{array}$} & \multirow[b]{3}{*}{$\%$} & \multirow[b]{3}{*}{$\begin{array}{l}\text { Gastos } \\
\text { totales }\end{array}$} \\
\hline & & & & & & & & & \\
\hline & $\begin{array}{c}\text { Gastos } \\
\text { generales }\end{array}$ & $\%$ & $\underset{\text { tración }}{\text { Adminis- }}$ & $\%$ & Total & $\%$ & & & \\
\hline $\begin{array}{l}1688-89 \\
1689-90 \\
1690-91 \\
1691-92 \\
1692-93\end{array}$ & $\begin{array}{l}511.320 \\
456.192 \\
368.094 \\
541.272 \\
414.798\end{array}$ & $\begin{array}{l}91,4 \\
90,5 \\
88,5 \\
91,8 \\
89,6\end{array}$ & $\begin{array}{l}48.000 \\
48.000 \\
48.000 \\
48.000 \\
48.000\end{array}$ & $\begin{array}{r}8,6 \\
9,5 \\
11,5 \\
8,2 \\
10,4\end{array}$ & $\begin{array}{l}559.320 \\
504.192 \\
416.094 \\
589.272 \\
462.798\end{array}$ & $\begin{array}{l}29,6 \\
30,3 \\
29,9 \\
25,2 \\
24,4\end{array}$ & $\begin{array}{r}1.326 .720 \\
1.158 .480 \\
976.320 \\
1.748 .880 \\
1.430 .880\end{array}$ & $\begin{array}{l}70,4 \\
69,7 \\
70,1 \\
74,8 \\
75,6\end{array}$ & $\begin{array}{l}1.886 .040 \\
1.662 .672 \\
1.392 .414 \\
2.338 .152 \\
1.893 .678\end{array}$ \\
\hline Media & 458.335 & 90,5 & 48.000 & 9,5 & 506.335 & 27,6 & 1.328 .256 & 72,4 & 1.834 .591 \\
\hline $\begin{array}{l}1695-96 \\
1696-97 \\
1697-98 \\
1698-99 \\
1699-1700\end{array}$ & $\begin{array}{r}262.339 \\
829.776 \\
569.676 \\
370.332 \\
60.240\end{array}$ & $\begin{array}{l}84.5 \\
94,5 \\
92,2 \\
88,5 \\
88,3\end{array}$ & $\begin{array}{l}48.000 \\
48.000 \\
48.000 \\
48.000 \\
48.000\end{array}$ & $\begin{array}{r}15,5 \\
5,5 \\
7,8 \\
11,5 \\
11,7\end{array}$ & $\begin{array}{r}310.339 \\
877.776 \\
617.676 \\
418.332 \\
68.240\end{array}$ & $\begin{array}{r}15,0 \\
54,9 \\
40,1 \\
40,8 \\
8,4\end{array}$ & $\begin{array}{r}1.755 .744 \\
719.328 \\
923.932 \\
606.000 \\
740.064\end{array}$ & $\begin{array}{l}85,0 \\
45,1 \\
59,9 \\
59,2 \\
91,6\end{array}$ & $\begin{array}{r}2.066 .083 \\
1.597 .104 \\
1.541 .628 \\
1.024 .332 \\
808.304\end{array}$ \\
\hline Media & 418.476 & 89,7 & 48.000 & 10,3 & 466.476 & 32,9 & 949.017 & 67,1 & 1.415 .493 \\
\hline $\begin{array}{l}1772-73 \\
1773-74 \\
1774-75\end{array}$ & $\begin{array}{l}94.554 \\
45.228 \\
60.000\end{array}$ & $\begin{array}{l}61,2 \\
42,9 \\
50,0\end{array}$ & $\begin{array}{l}60.000 \\
60.000 \\
60.000\end{array}$ & $\begin{array}{l}38,8 \\
57,1 \\
50,0\end{array}$ & $\begin{array}{l}154.554 \\
105.228 \\
120.000\end{array}$ & & & & $\begin{array}{l}154.554 \\
105.228 \\
120.000\end{array}$ \\
\hline Media & 66.594 & 52,6 & 60.000 & 47,4 & 126.594 & & & & 126.594 \\
\hline
\end{tabular}

Fuente: A. M. Macf́as Hernández, Economia y sociedad en Canarias durante el Antiguo Régimen (tesis doctoral inédita), Universidad Nacional de Educación a Distancia, Madrid, 1985. 


\section{CUADRO II (Continuación)}

Estructura de los gastos realizados por el propietario en la gestión directa $y$ en la medianeria: caso de la bacienda de Los Principes

\begin{tabular}{|c|c|c|c|c|c|c|c|}
\hline \multirow[b]{3}{*}{ Allos } & \multirow{2}{*}{\multicolumn{6}{|c|}{$\begin{array}{l}\text { EXPLOTACION DIRECTA } \\
\text { GASTOS DE EXPLOTACION }\end{array}$}} & \multirow[b]{3}{*}{$\begin{array}{l}\text { Gastos } \\
\text { totales }\end{array}$} \\
\hline & & & & & & & \\
\hline & \multirow{2}{*}{$\frac{\text { Salarios }}{1.881 .084}$} & \multirow{2}{*}{$\frac{\%}{76,8}$} & \multirow{2}{*}{$\begin{array}{c}\begin{array}{c}\text { Gastos } \\
\text { generales }\end{array} \\
340.527\end{array}$} & \multirow{2}{*}{$\frac{\%}{13,9}$} & \multirow{2}{*}{$\begin{array}{c}\begin{array}{c}\text { Adminis- } \\
\text { tracion }\end{array} \\
228.672\end{array}$} & \multirow{2}{*}{$\frac{\%}{9,3}$} & \\
\hline $1734-38$ * & & & & & & & 2.450 .283 \\
\hline $\begin{array}{l}1738-39 \\
1739-40 \\
1740-41 \\
1741-42\end{array}$ & $\begin{array}{l}1.279 .979 \\
1.215 .951 \\
1.251 .511 \\
1.131 .451\end{array}$ & $\begin{array}{l}71,8 \\
70,8 \\
71,5 \\
69,6\end{array}$ & $\begin{array}{l}275.015 \\
274.218 \\
268.633 \\
265.129\end{array}$ & $\begin{array}{l}15,4 \\
15,9 \\
15,4 \\
16,3\end{array}$ & $\begin{array}{l}228.672 \\
228.672 \\
228.672 \\
228.672\end{array}$ & $\begin{array}{l}12,8 \\
13,3 \\
13,1 \\
14,1\end{array}$ & $\begin{array}{l}1.783 .666 \\
1.718 .841 \\
1.748 .816 \\
1.625 .252\end{array}$ \\
\hline Media & 1.219 .723 & 70,9 & 270.748 & 15,7 & 228.672 & 13,4 & 1.719 .143 \\
\hline $\begin{array}{l}1742-43 \\
1743-44 \\
1744-45 \\
1745-46\end{array}$ & $\begin{array}{l}1.107 .710 \\
1.270 .386 \\
1.194 .618 \\
1.194 .165\end{array}$ & $\begin{array}{l}70,6 \\
72,0 \\
71,8 \\
72,4\end{array}$ & $\begin{array}{l}231.433 \\
266.250 \\
241.203 \\
226.740\end{array}$ & $\begin{array}{l}14,8 \\
15,1 \\
14,5 \\
13,7\end{array}$ & $\begin{array}{l}228.672 \\
228.672 \\
228.672 \\
228.672\end{array}$ & $\begin{array}{l}14,6 \\
12,9 \\
13,7 \\
13,9\end{array}$ & $\begin{array}{l}1.567 .815 \\
1.765 .308 \\
1.664 .493 \\
1.649 .577\end{array}$ \\
\hline Media & 1.191 .719 & 71,7 & 241.406 & 14,5 & 228.672 & 13,8 & 1.661 .797 \\
\hline $\begin{array}{l}1746-47 \\
1747-48 \\
1748-49 \\
1749-50\end{array}$ & $\begin{array}{l}1.162 .902 \\
1.130 .313 \\
1.059 .046 \\
1.094 .045\end{array}$ & $\begin{array}{l}70,3 \\
70,1 \\
68,4 \\
70,7\end{array}$ & $\begin{array}{l}261.897 \\
253.848 \\
260.872 \\
225.582\end{array}$ & $\begin{array}{l}15,8 \\
15,7 \\
16,8 \\
14,3\end{array}$ & $\begin{array}{l}228.672 \\
228.672 \\
228.672 \\
228.672\end{array}$ & $\begin{array}{l}13,9 \\
14,2 \\
14,8 \\
14,8\end{array}$ & $\begin{array}{l}1.653 .471 \\
1.612 .833 \\
1.548 .590 \\
1.548 .299\end{array}$ \\
\hline Media & 1.111 .576 & 69,9 & 250.549 & 15,7 & 228.672 & 14,4 & 1.590 .799 \\
\hline $\begin{array}{l}1750-51 \\
1751-52 \\
1752-53 \\
1753-54 \\
1754-55 \\
1755-56\end{array}$ & $\begin{array}{r}880.224 \\
902.107 \\
1.040 .742 \\
1.100 .766 \\
1.102 .432 \\
1.134 .146\end{array}$ & $\begin{array}{l}66,0 \\
67,2 \\
69,3 \\
70,3 \\
71,1 \\
70,2\end{array}$ & $\begin{array}{l}224.304 \\
212.406 \\
232.098 \\
235.848 \\
219.642 \\
253.269\end{array}$ & $\begin{array}{l}16,8 \\
15,8 \\
15,4 \\
15,1 \\
14,2 \\
15,7\end{array}$ & $\begin{array}{l}228.672 \\
228.672 \\
228.672 \\
228.672 \\
228.672 \\
228.672\end{array}$ & $\begin{array}{l}17,2 \\
17,0 \\
15,3 \\
14,6 \\
14,7 \\
14,1\end{array}$ & $\begin{array}{l}1.333 .200 \\
1.343 .185 \\
1.501 .512 \\
1.565 .286 \\
1.550 .746 \\
1.616 .087\end{array}$ \\
\hline Media & 1.026 .736 & 69,1 & 229.594 & 15,5 & 228.672 & 15,4 & 1.485 .002 \\
\hline
\end{tabular}

* Gastos medios del cuatrienio, dado que la contabilidad ofrece los datos agregados. 


\section{CUADRO}

Los ingresos de la gestión directa de las explotaciones

\begin{tabular}{|c|c|c|c|c|c|c|c|c|c|c|}
\hline \multirow[b]{3}{*}{$A \tilde{n} o s$} & \multicolumn{5}{|c|}{ COSECHA ANUAL } & \multirow{2}{*}{\multicolumn{2}{|c|}{$\begin{array}{c}\text { Precios medios } \\
\text { ponderados } \\
\text { (mrs } / \text { br. })\end{array}$}} & \multirow{3}{*}{$\begin{array}{c}\text { Ingresos } \\
\text { brutos } \\
\text { (mrs.) }\end{array}$} & & \\
\hline & \multicolumn{2}{|c|}{ Malvasia } & \multicolumn{2}{|c|}{ Vidueño } & \multirow{2}{*}{$\begin{array}{l}\text { Total } \\
\text { (brs.) }\end{array}$} & & & & \multicolumn{2}{|c|}{ Salarios } \\
\hline & brs. & $\%$ & brs. & $\%$ & & Malv. & Vid. & & mrs. & $\%$ \\
\hline $\begin{array}{l}1700-01 \\
1701-02 \\
1702-03 \\
1703-04 \\
1704-05 \\
1705-06 \\
1706-07\end{array}$ & $\begin{array}{l}693,3 \\
533,3 \\
720,0 \\
440,0 \\
706,6 \\
600,0 \\
393,3\end{array}$ & $\begin{array}{l}85,0 \\
85,7 \\
95,8 \\
82,3 \\
92,2 \\
92,3 \\
87,6\end{array}$ & $\begin{array}{r}122,2 \\
88,9 \\
31,1 \\
94,4 \\
60,0 \\
50,0 \\
55,6\end{array}$ & $\begin{array}{r}15,0 \\
14,3 \\
4,2 \\
17,7 \\
7,8 \\
7,7 \\
12,4\end{array}$ & $\begin{array}{l}815,2 \\
622,2 \\
751,1 \\
534,4 \\
766,6 \\
650,0 \\
448,9\end{array}$ & $\begin{array}{l}1.580 \\
1.160 \\
1.840 \\
1.120 \\
1.200 \\
1.200 \\
1.460\end{array}$ & $\begin{array}{l}600 \\
600 \\
600 \\
600 \\
600 \\
600 \\
600\end{array}$ & $\begin{array}{r}1.168 .734 \\
671.968 \\
1.343 .460 \\
549.440 \\
883.920 \\
750.000 \\
607.578\end{array}$ & $\begin{array}{l}541.584 \\
455.280 \\
585.360 \\
528.960 \\
506.280 \\
499.488 \\
484.992\end{array}$ & $\begin{array}{l}72,6 \\
66,8 \\
73,3 \\
77,6 \\
76,2 \\
74,1 \\
72,2\end{array}$ \\
\hline Media & 583,7 & 89,1 & 71,7 & 10,9 & 655,4 & 1.365 & 600 & 839.225 & 514.563 & 73,2 \\
\hline $\begin{array}{l}1712-13 \\
1713-14 \\
1714-15 \\
1715-16 \\
1716-17\end{array}$ & $\begin{array}{l}440,0 \\
191,1 \\
306,6 \\
400,0 \\
346,6\end{array}$ & $\begin{array}{l}86,8 \\
33,1 \\
92,0 \\
92,1 \\
80,2\end{array}$ & $\begin{array}{r}66,6 \\
386,6 \\
26,6 \\
34,4 \\
85,5\end{array}$ & $\begin{array}{r}13,2 \\
66,9 \\
8,0 \\
7,9 \\
19,8\end{array}$ & $\begin{array}{l}506,6 \\
577,7 \\
333,2 \\
434,4 \\
432,1\end{array}$ & $\begin{array}{l}1.676 \\
1.851 \\
1.502 \\
1.240 \\
1.363\end{array}$ & $\begin{array}{l}660 \\
833 \\
833 \\
308 \\
308\end{array}$ & $\begin{array}{l}781.396 \\
675.764 \\
482.671 \\
506.595 \\
498.749\end{array}$ & $\begin{array}{l}322.932 \\
320.868 \\
300.768 \\
295.008\end{array}$ & $\begin{array}{l}65,9 \\
69,3 \\
70,9 \\
70,3\end{array}$ \\
\hline Media & 336,8 & 73,7 & 119,9 & 26,3 & 456,7 & 1.526 & 588 & 584.458 & 309.894 & 69,0 \\
\hline
\end{tabular}

Fuente: A. M. Macías Hernández, Economia y sociedad en Canarias durante el Antiguo Régimen (tesis doctoral inédita), Universidad Nacional de Educación a Distancia, Madrid, 1985. 
iticolas del conde del Valle de Salazar (Tenerife)

GASTOS DE EXPLOTACION

\begin{tabular}{|c|c|c|c|c|c|c|c|c|c|}
\hline \multicolumn{2}{|c|}{ Generales } & \multicolumn{2}{|c|}{ Administración } & \multicolumn{2}{|c|}{ Transporte } & \multirow{2}{*}{$\begin{array}{c}\text { Total } \\
\text { (mrs.) }\end{array}$} & \multirow{2}{*}{$\begin{array}{c}\text { Coste } \\
\text { labores } \\
\text { (mrs/br.) }\end{array}$} & \multirow{2}{*}{$\begin{array}{c}\text { Ingresos } \\
\text { netos } \\
\text { (mrs.) }\end{array}$} & \multirow{2}{*}{$\begin{array}{l}\text { Cuota de } \\
\text { beneficio }\end{array}$} \\
\hline mrs. & $\%$ & mrs. & $\%$ & mrs. & $\%$ & & & & \\
\hline $\begin{array}{r}98.736 \\
108.060 \\
71.424 \\
54.660 \\
50.196 \\
60.492 \\
87.420\end{array}$ & $\begin{array}{r}13,2 \\
15,9 \\
8,9 \\
8,0 \\
7,6 \\
9,0 \\
13,0\end{array}$ & $\begin{array}{l}83.904 \\
83.904 \\
83,904 \\
83.904 \\
83.904 \\
83.904 \\
83.904\end{array}$ & $\begin{array}{l}11,2 \\
12,3 \\
10,5 \\
12,3 \\
12,6 \\
12,4 \\
12,5\end{array}$ & $\begin{array}{l}21.912 \\
34.200 \\
57.984 \\
14.136 \\
24.000 \\
30.540 \\
15.432\end{array}$ & $\begin{array}{l}3,0 \\
5,0 \\
7,3 \\
2,1 \\
3,6 \\
4,5 \\
2,3\end{array}$ & $\begin{array}{l}746.136 \\
681.444 \\
798.672 \\
681.660 \\
664.380 \\
674.424 \\
671.748\end{array}$ & $\begin{array}{r}915,3 \\
1.095,2 \\
1.063,3 \\
1.275,6 \\
866,6 \\
1.037,6 \\
1.496,4\end{array}$ & $\begin{array}{r}422.598 \\
-9.476 \\
544.788 \\
-132.220 \\
219.540 \\
75.576 \\
-64.170\end{array}$ & $\begin{array}{r}56,6 \\
-1,4 \\
68,2 \\
-19,4 \\
33,0 \\
11,2 \\
-9,6\end{array}$ \\
\hline 75.855 & 10,8 & 83.904 & 12,0 & 28.314 & 4,0 & 702.637 & $1.072,1$ & 136.588 & 19,4 \\
\hline $\begin{array}{l}64.896 \\
56.124 \\
38.520 \\
37.896\end{array}$ & $\begin{array}{r}13,3 \\
12,1 \\
9,1 \\
9,0\end{array}$ & $\begin{array}{l}74.304 \\
74.304 \\
74.304 \\
74.304\end{array}$ & $\begin{array}{l}15,2 \\
16,1 \\
17,5 \\
17,7\end{array}$ & $\begin{array}{l}27.576 \\
11.412 \\
11.760 \\
12.720\end{array}$ & $\begin{array}{l}5,6 \\
2,5 \\
2,7 \\
3,0\end{array}$ & $\begin{array}{l}489.708 \\
462.708 \\
425.352 \\
419.928\end{array}$ & $\begin{array}{r}1.034,4 \\
847,7 \\
1.388,7 \\
979,2 \\
971,8\end{array}$ & $\begin{array}{r}257.344 \\
186.056 \\
19.963 \\
81.243 \\
78.821\end{array}$ & $\begin{array}{r}49,1 \\
38,0 \\
4,3 \\
19,1 \\
18,8 \\
200\end{array}$ \\
\hline 49.359 & 11,0 & 74.304 & 16,5 & 15.867 & 3,5 & 449.424 & 984,1 & 135.034 & 30,0 \\
\hline
\end{tabular}




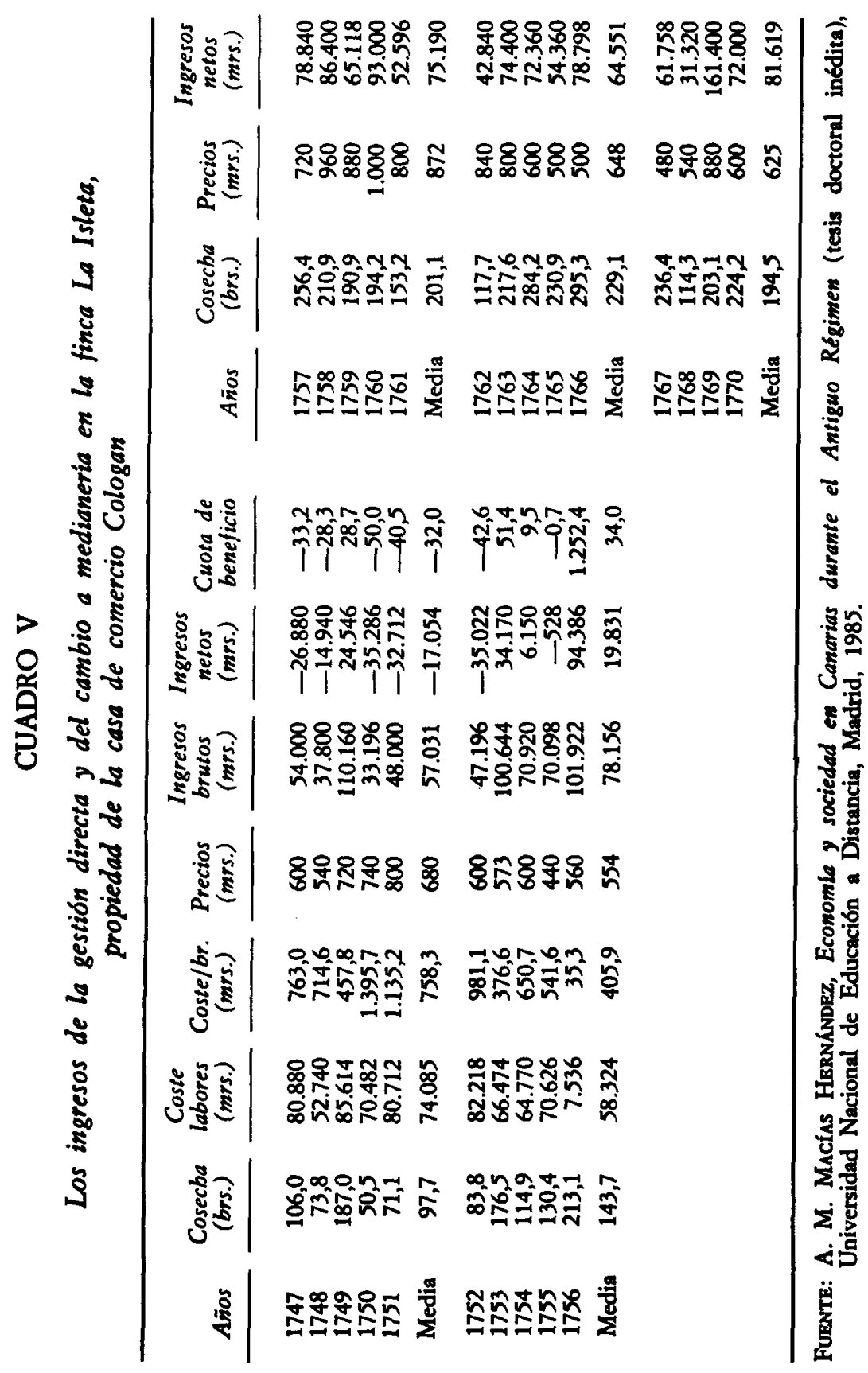




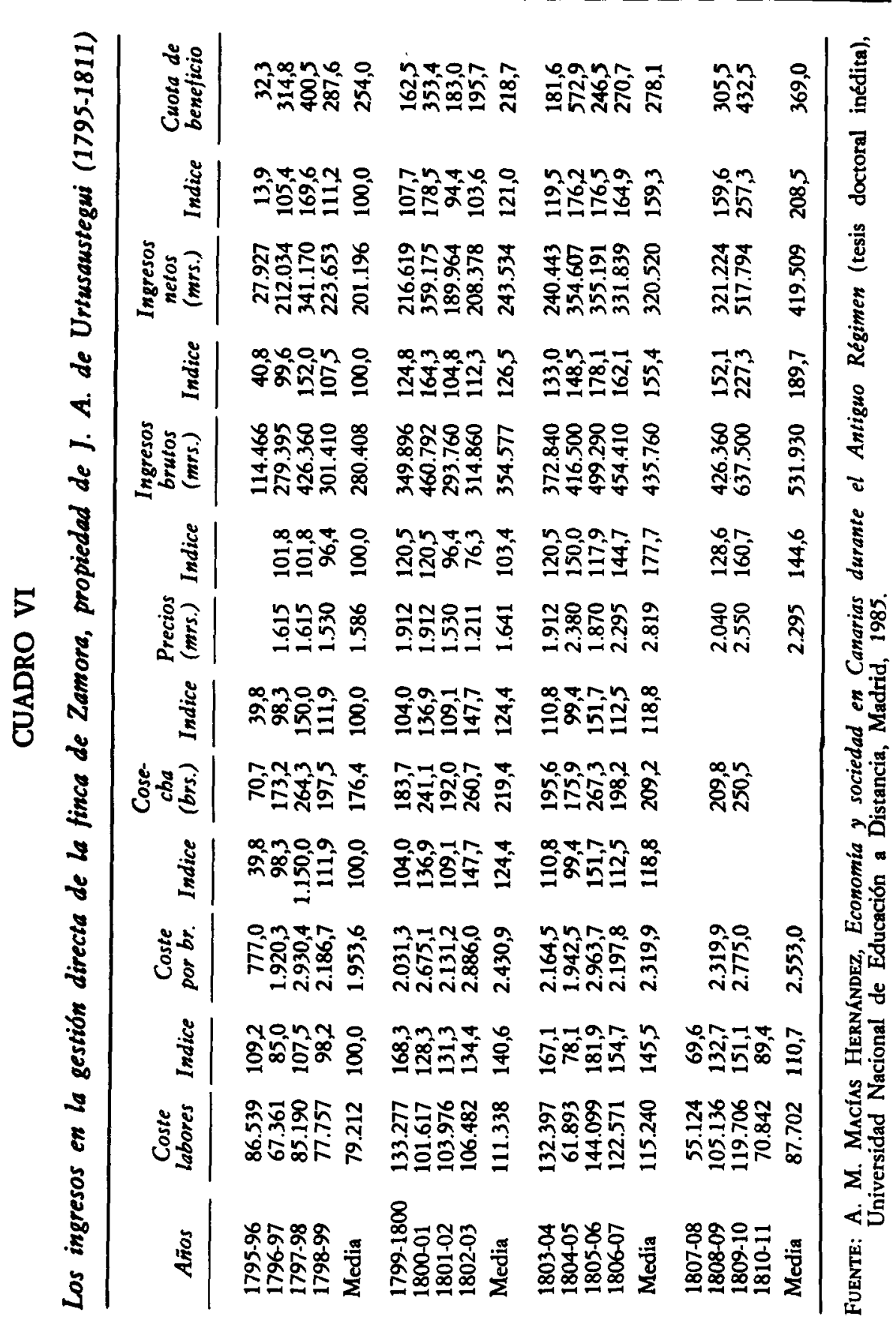




\section{CUADRO VII}

Los beneficios derivados de la comercialización de la parte de cosecha correspondiente a los medianeros de la bacienda de Los Principes

\begin{tabular}{|c|c|c|c|c|c|c|}
\hline \multirow[b]{2}{*}{ Años } & \multicolumn{3}{|c|}{$\begin{array}{c}\text { Gastos comercialización } \\
\text { cosecha medianero }\end{array}$} & \multirow[b]{2}{*}{$\begin{array}{c}\text { Ingresos } \\
\text { brutos } \\
\text { de su venta }\end{array}$} & \multirow[b]{2}{*}{$\begin{array}{c}\text { Ingresos } \\
\text { netos } \\
\text { de su venta }\end{array}$} & \multirow[b]{2}{*}{$\begin{array}{l}\text { Cuota de } \\
\text { beneficio }\end{array}$} \\
\hline & $\begin{array}{l}\text { Valor } \\
\text { cosecha }\end{array}$ & $\begin{array}{c}\text { Mitad } \\
\text { gastos } \\
\text { generales* }\end{array}$ & $\begin{array}{l}\text { Total } \\
\text { gastos }\end{array}$ & & & \\
\hline $\begin{array}{l}1688-89 \\
1689-90 \\
1690-91 \\
1691-92 \\
1692-93\end{array}$ & $\begin{array}{r}1.326 .720 \\
1.158 .480 \\
976.320 \\
1.748 .880 \\
1.430 .880\end{array}$ & $\begin{array}{l}255.660 \\
228.096 \\
184.047 \\
270.636 \\
207.399\end{array}$ & $\begin{array}{l}1.582 .380 \\
1.386 .576 \\
1.160 .367 \\
2.019 .516 \\
1.638 .279\end{array}$ & $\begin{array}{l}2.246 .088 \\
3.028 .490 \\
3.812 .134 \\
2.567 .640 \\
3.996 .271\end{array}$ & $\begin{array}{r}663.708 \\
1.641 .914 \\
2.651 .767 \\
548.124 \\
2.357 .992\end{array}$ & $\begin{array}{r}41,9 \\
118,4 \\
228,5 \\
27,1 \\
143,9\end{array}$ \\
\hline Media & 1.328 .256 & 229.167 & 1.557 .423 & 3.130 .124 & 1.572 .701 & 100,9 \\
\hline $\begin{array}{l}1695-96 \\
1696-97 \\
1697-98 \\
1698-99 \\
1699-1700\end{array}$ & $\begin{array}{r}1.755 .744 \\
719.328 \\
923.952 \\
606.000 \\
740.064\end{array}$ & $\begin{array}{r}131.169 \\
414.888 \\
284.838 \\
185.166 \\
30.120\end{array}$ & $\begin{array}{r}1.886 .913 \\
1.134 .216 \\
1.208 .790 \\
791.166 \\
770.184\end{array}$ & $\begin{array}{l}3.236 .976 \\
2.034 .189 \\
2.162 .736 \\
1.333 .836 \\
1.937 .934\end{array}$ & $\begin{array}{r}1.350 .063 \\
899.973 \\
953.946 \\
542.670 \\
1.167 .750\end{array}$ & $\begin{array}{r}71,5 \\
79,3 \\
78,9 \\
68,6 \\
151,6\end{array}$ \\
\hline Media & 949.017 & 209.238 & 1.158 .255 & 2.141 .134 & 982.879 & 84,9 \\
\hline
\end{tabular}

* En los gastos generales de explotación hemos incluido todos aquellos relacionados con el proceso de encierro del mosto, arreglo de pipas y bodegas, etc.; puede considerarse que la mitad de estos gastos se deben a la proporción de cosecha correspondiente al medianero y adquirida por el propietario. Indudablemente, habria que haber considerado también en este cálculo las amortizaciones del capital fijo representado por las bodegas, lagares, etc., los cuales no posee el medianero; pero ello es imposible.

Fugnte: A. M. Macf́as Hernández, Economia y sociedad en Canarias durante el Antiguo Régimen (tesis doctoral inédita), Universidad Nacional de Educación a Distancia, Madrid, 1985. 


\section{CUADRO VIII}

Los beneficios derivados de la comercialización de la parte de cosecha correspondiente a los medianeros de J. A. de Urtusaustegui

\begin{tabular}{|c|c|c|c|c|c|c|c|c|c|}
\hline \multirow[b]{3}{*}{ Años } & \multirow{2}{*}{\multicolumn{3}{|c|}{ Mosto de las *medias» }} & \multicolumn{3}{|c|}{ PRECIOS (mrs/br.) } & \multirow{3}{*}{$\begin{array}{c}\text { Valor } \\
\text { mosto } \\
\text { «medias» } \\
(\text { mrs.) }\end{array}$} & \multirow{3}{*}{$\begin{array}{c}\text { Valor } \\
\text { en venta } \\
\text { (mrs.) }\end{array}$} & \multirow{3}{*}{$\begin{array}{l}\text { Prés- } \\
\text { tamos } \\
\text { (mrs.) }\end{array}$} \\
\hline & & & & \multicolumn{2}{|c|}{$\begin{array}{c}\text { Mosto } \\
\text { smedias }\end{array}$} & \multirow{2}{*}{$\begin{array}{c}\text { Venta } \\
\text { propie- } \\
\text { tario }\end{array}$} & & & \\
\hline & $\begin{array}{l}\text { Malv. } \\
\text { (brs.) }\end{array}$ & $\begin{array}{l}\text { Vid. } \\
\text { (brs.) }\end{array}$ & $\begin{array}{l}\text { Total } \\
\text { (brs.) }\end{array}$ & Malv. & Vid. & & & & \\
\hline $\begin{array}{l}1788 \\
1789 \\
1790 \\
1791 \\
1792\end{array}$ & $\begin{array}{r}106,3 \\
167,6 \\
240,8 \\
156,3 \\
25,2\end{array}$ & & & $\begin{array}{l}1.403 \\
1.275 \\
1.020 \\
1.275 \\
1.403\end{array}$ & & & $\begin{array}{r}149.140 \\
137.190 \\
245.616 \\
199.282 \\
35.356\end{array}$ & & $\begin{array}{l}240.454 \\
302.651 \\
273.950 \\
263.065 \\
199.751\end{array}$ \\
\hline Media & 139,2 & & & 1.275 & & & 153.317 & & 255.974 \\
\hline $\begin{array}{l}1793 \\
1794 \\
1795 \\
1796 \\
1797\end{array}$ & $\begin{array}{r}30,3 \\
183,9 \\
146,0 \\
57,0 \\
180,3\end{array}$ & $\begin{array}{l}14,3 \\
34,5\end{array}$ & $\begin{array}{r}71,3 \\
214,8\end{array}$ & $\begin{array}{l}1.403 \\
1.530 \\
1.530 \\
2.040 \\
2.040\end{array}$ & $\begin{array}{l}1.913 \\
1.870\end{array}$ & $\begin{array}{l}2.350 \\
2.500 \\
2.280 \\
2.500\end{array}$ & $\begin{array}{r}42.511 \\
158.967 \\
223.380 \\
143.636 \\
432.327\end{array}$ & $\begin{array}{l}244.165 \\
365.000 \\
162.564 \\
537.000\end{array}$ & $\begin{array}{l}215.316 \\
237.206 \\
195.339 \\
131.304 \\
299.756\end{array}$ \\
\hline Media & 119,5 & & & 1.709 & 1.892 & 2.408 & 200.164 & 327.182 & 215.784 \\
\hline $\begin{array}{l}1798 \\
1799 \\
1800 \\
1801 \\
1802\end{array}$ & $\begin{array}{l}140,9 \\
141,4 \\
157,6 \\
162,8 \\
204,5\end{array}$ & $\begin{array}{l}36,2 \\
44,4 \\
27,2 \\
38,8 \\
43,0\end{array}$ & $\begin{array}{l}177,1 \\
185,8 \\
184,8 \\
201,6 \\
247,5\end{array}$ & $\begin{array}{l}1.403 \\
1.530 \\
1.913 \\
1.913 \\
1.530\end{array}$ & $\begin{array}{l}1.741 \\
1.339 \\
2.465 \\
2.390 \\
1.211\end{array}$ & $\begin{array}{l}1.900 \\
2.300 \\
2.825 \\
2.400 \\
2.250\end{array}$ & $\begin{array}{l}260.707 \\
275.794 \\
368.537 \\
404.168 \\
364.958\end{array}$ & $\begin{array}{l}336.490 \\
427.340 \\
522.060 \\
483.840 \\
556.875\end{array}$ & $\begin{array}{l}240.430 \\
292.660 \\
283.806 \\
265.554 \\
260.098\end{array}$ \\
\hline Media & 161,4 & 37,9 & 199,4 & 1.658 & 1.829 & 2.335 & 334.833 & 465.321 & 268.510 \\
\hline $\begin{array}{l}1803 \\
1804 \\
1805 \\
1806 \\
1807\end{array}$ & $\begin{array}{l}275,0 \\
166,9 \\
140,5 \\
241,5 \\
223,1\end{array}$ & $\begin{array}{r}80,7 \\
35,1 \\
29,0 \\
112,0 \\
45,8\end{array}$ & $\begin{array}{l}355,7 \\
202,0 \\
169,5 \\
353,5 \\
268,9\end{array}$ & $\begin{array}{l}1.211 \\
1.913 \\
2.040 \\
1.530 \\
1.530\end{array}$ & $\begin{array}{l}1.020 \\
1.530 \\
\\
1.870 \\
1.870\end{array}$ & $\begin{array}{l}2.200 \\
2.750 \\
2.800 \\
2.200 \\
2.700\end{array}$ & $\begin{array}{l}415.339 \\
372.983 \\
345.780 \\
578.935 \\
426.989\end{array}$ & $\begin{array}{l}782.540 \\
555.500 \\
474.600 \\
777.700 \\
726.030\end{array}$ & $\begin{array}{l}294.895 \\
250.888 \\
314.032 \\
441.862 \\
418.092\end{array}$ \\
\hline Media & 209,4 & 60,5 & 269,9 & 1.645 & 1.572 & 2.530 & 428.005 & 663.274 & 343.954 \\
\hline $\begin{array}{l}1808 \\
1809 \\
1810 \\
1811\end{array}$ & $\begin{array}{r}75,9 \\
183,9 \\
275,3 \\
191,1\end{array}$ & $\begin{array}{l}31,2 \\
38,6 \\
58,5 \\
39,2\end{array}$ & $\begin{array}{l}107,1 \\
222,5 \\
333,8 \\
230,3\end{array}$ & $\begin{array}{l}1.785 \\
2.040 \\
2.550 \\
3.060\end{array}$ & $\begin{array}{l}1.530 \\
1.870 \\
2.380 \\
2.890\end{array}$ & $\begin{array}{l}2.600 \\
2.900 \\
4.000 \\
4.500\end{array}$ & $\begin{array}{l}183.217 \\
447.338 \\
841.245 \\
698.054\end{array}$ & $\begin{array}{r}278.460 \\
645.250 \\
1.335 .200 \\
1.036 .350\end{array}$ & $\begin{array}{l}279.407 \\
469.476 \\
362.654 \\
364.651\end{array}$ \\
\hline Media & 145,2 & 41,9 & 173,4 & 2.359 & 2.168 & 3.500 & 542.463 & 823.815 & 369.017 \\
\hline
\end{tabular}

Fuente: A. M. Macías Hernández, Economía y sociedad en Canarias durante el Antiguo Régimen (tesis doctoral inédita), Universidad Nacional de Educación a Distancia, Madrid, 1985. 


\section{CUADRO IX}

Los ingresos nominales del medianero viticultor: el ejemplo de las grandes baciendas (en mrs. de Canarias)

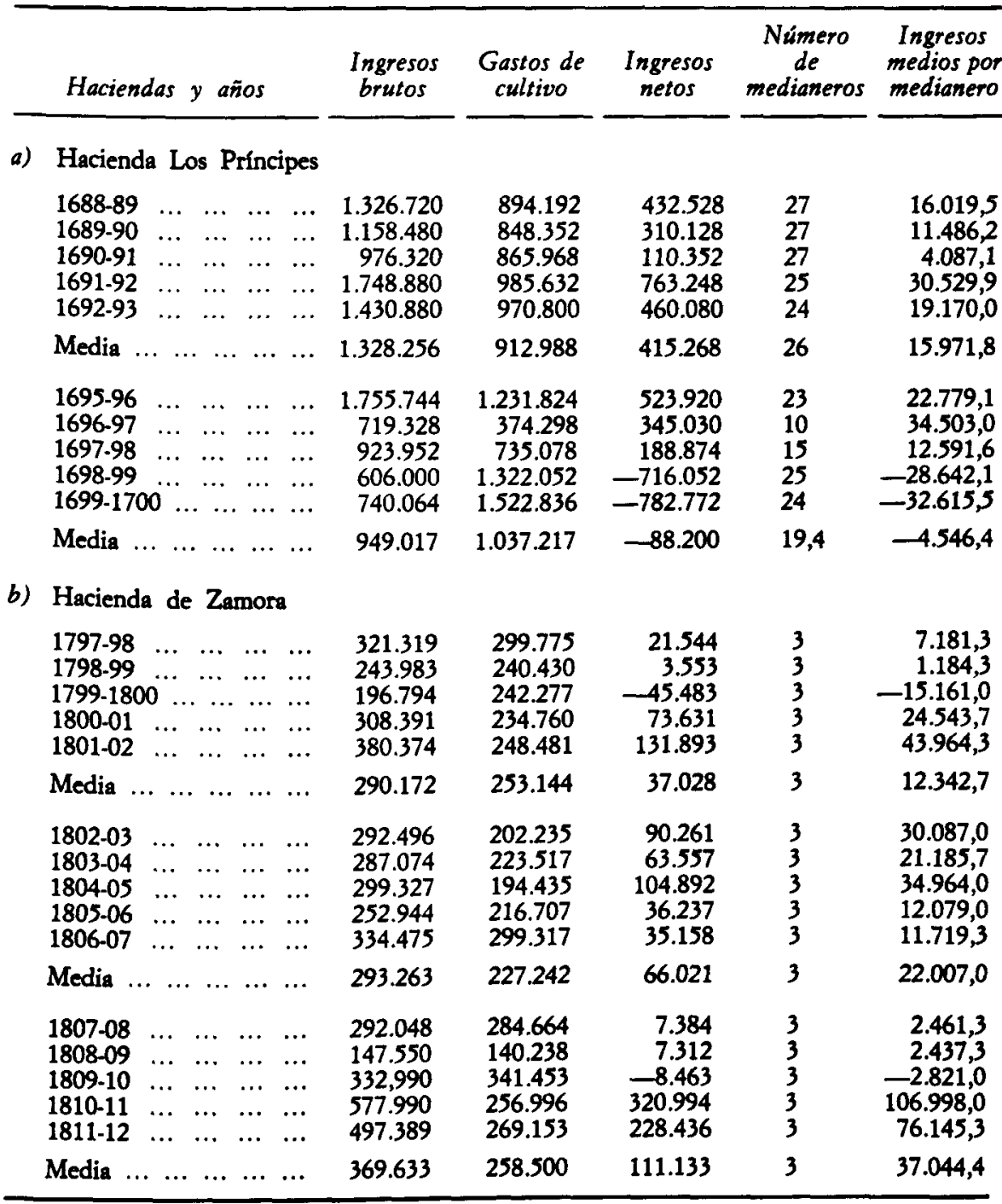

Furnte: A. M. Macías Hernández, Economía y sociedad en Canarias durante el Antiguo Régimen (tesis doctoral inédita), Universidad Nacional de Educación a Distancia, Madrid, 1985. 